\title{
N-3 Polyunsaturated Fatty Acids and Atrial Fibrillation: Friend or Foe?
}

\author{
Gary Tse ${ }^{1} \cdot$ Leonardo Roever ${ }^{2} \cdot$ Tong Liu $^{3}$ \\ Published online: 2 April 2019 \\ (C) Springer Science+Business Media, LLC, part of Springer Nature 2019
}

Recently, two randomized controlled trials (RCTs) on longchain n-3 polyunsaturated fatty acids (n-3 PUFAs) or their derivatives and cardiovascular risk have been published $[1$, 2]. The REDUCE-IT trial found that the icosapent ethyl of eicosapentaenoic acid (EPA) (4 g) reduced the primary endpoint (cardiovascular death, nonfatal myocardial infarction, nonfatal stroke, coronary revascularization, or unstable angina) but increased atrial fibrillation (AF) incidence [1]. By contrast, the VITAL Trial reported that no significant benefit of EPA $(460 \mathrm{mg})$ and docosahexaenoic acid $(380 \mathrm{mg})$ on their primary composite endpoint (cardiovascular death, myocardial infarction, stroke), but did not report on AF events [2]. Previously, our meta-analysis of ten RCTs found that n-3 PUFAs did not protect against incident or recurrent AF [3]. In real-world settings, a meta-analysis of seven prospective cohort studies also found no protection of n-3 PUFAs against AF development [4]. Yet, the Cardiovascular Health Study associated higher levels of n-3 PUFAs and a lower incidence of AF [5]. Given these conflicting findings, more detailed studies are needed to determine whether fatty acid supplements can effectively prevent AF [6]. Experimental studies in animal models can provide insights as to whether $n-3$ PUFAs can reduce inflammation [7] and atrial fibrosis that serves as the substrate for fibrillation [8]. Real-world studies and RCTs will need to assess baseline red cell and plasma

Leonardo Roever

leonardoroever@hotmail.com

Tong Liu

liutongdoc@126.com

1 Department of Medicine and Therapeutics, Li Ka Shing Institute of Health Sciences, Faculty of Medicine, Chinese University of Hong Kong, Shatin, Hong Kong, China

2 Department of Clinical Research, Federal University of Uberlândia, Uberlândia, MG, Brazil

3 Tianjin Key Laboratory of Ionic-Molecular Function of Cardiovascular Disease, Department of Cardiology, Tianjin Institute of Cardiology, Second Hospital of Tianjin Medical University, Tianjin 300211, China levels of n-3 PUFAs, omega-3 index, and their relationships to $\mathrm{AF}$ as a primary endpoint.

\section{Compliance with Ethical Standards}

Conflict of Interest Gary Tse, Leonardo Roever, and Tong Liu declare no conflict of interest.

Human and Animal Rights and Informed Consent This article does not contain any studies with human or animal subjects performed by any of the authors.

\section{References}

1. Bhatt DL, Steg PG, Miller M, et al: Cardiovascular risk reduction with icosapent ethyl for hypertriglyceridemia. N Engl J Med 2018.

2. Manson JE, Cook NR, Lee IM, et al: Marine n-3 fatty acids and prevention of cardiovascular disease and cancer. N Engl J Med 2018.

3. Liu T, Korantzopoulos P, Shehata M, Li G, Wang X, Kaul S. Prevention of atrial fibrillation with omega-3 fatty acids: a metaanalysis of randomised clinical trials. Heart. 2011;97(13):1034-40.

4. Li F-R, Chen G-C, Qin J, Wu X. Dietary fish and long-chain n-3 polyunsaturated fatty acids intake and risk of atrial fibrillation: a meta-analysis. Nutrients. 2017;9(9):955.

5. Wu JHY, Lemaitre RN, King IB, Song X, Sacks FM, Rimm EB, et al. Association of plasma phospholipid long-chain $\omega-3$ fatty acids with incident atrial fibrillation in older adults: the cardiovascular health study. Circulation. 2012;125(9):1084-93.

6. Tribulova N, Szeiffova Bacova B, Egan Benova T, Knezl V, Barancik M, Slezak J. Omega-3 index and anti-arrhythmic potential of omega-3 PUFAs. Nutrients. 2017;9(11).

7. Korantzopoulos P, Letsas KP, Tse G, Fragakis N, Goudis CA, Liu T. Inflammation and atrial fibrillation: a comprehensive review. $\mathrm{J}$ Arrhythm. 2018;34(4):394-401.

8. Tse G, Yan BP, Chan YWF, Tian XY, Huang Y: Reactive oxygen species, endoplasmic reticulum stress and mitochondrial dysfunction: the link with cardiac arrhythmogenesis. Front Physiol 2016, $7(313)$.

Publisher's Note Springer Nature remains neutral with regard to jurisdictional claims in published maps and institutional affiliations. 